\title{
Medicolegal
}

\section{Dr Ann Dally's continued brushes with the GMC}

\author{
CLARE DYER
}

The judicial committee of the Privy Council last week turned down Dr Ann Dally's appeal against the General Medical Council's finding that she was guilty of serious professional misconduct in irresponsibly prescribing controlled drugs. Dr Dally, aged 60, a veteran private practitioner specialising in addiction treatment and a longstanding advocate of stabilisation treatment for chronic drug addicts, is now prohibited, as a condition of her registration, from possessing or prescribing controlled drugs for a 14 month period from 15 September 1987. Before the period elapses, having considered her case further, the GMC may revoke or vary the condition or extend the period. Dr Dally will be asked to supply the names of professional colleagues and "other persons of standing" who can testify to her conduct during the period of conditional registration. If the GMC finds that she has failed to comply with the condition her registration can be suspended or erased.

This is not Dr Dally's first brush with the GMC. In 1983, while sitting as a member of the Medical Working Group on Drug Dependence, which produced the Guidelines of Good Clinical Practice in the Treatment of Drug Misuse-the document that enshrines current official policy on the treatment of drug addictsshe was found guilty of serious professional misconduct on similar charges and admonished. ${ }^{\mathrm{r}}$ The decision to ban her from possessing or prescribing controlled drugs was made in the light of "your blatant failure to heed the warning conveyed to you by your previous appearance before this committee," she was told.

This time Dr Dally was charged under two heads. Firstly, it was alleged that, in return for fees, she issued numerous prescriptions for methadone hydrochloride and other drugs in an irresponsible manner. The second head of the charge related to a particular patient, Mr A. Dr Dally was charged with issuing numerous prescriptions for controlled drugs to Mr A between February 1982 and October 1985 in an irresponsible manner and, in particular, without conducting a conscientious and sufficient physical examination at the first consultation or adequately monitoring his progress; and with discharging him from her care without making arrangements for another practitioner to take over his treatment.

Under the first head the allegations against her were that she treated so many addicts that she could not treat them all conscientiously and properly; that she prescribed privately to some addicts who could not be expected to have the means to meet the fees and dispensing charges without resorting to crime; that she prescribed excessively large amounts of methadone on single prescriptions;

London NW1

CLARE DYER, BA, BLS, legal correspondent that she accepted addicts who lived far away from her surgery, some from areas where there were NHS treatment facilities; that in the case of the majority of patients in the committee's schedules there had been no noticeable attempt to reduce the dosage; and that she failed to follow the guidelines for good clinical practice.

The professional conduct committee found the second head proved but not the first. Before the Privy Council Dr Dally's counsel argued that the finding against her on the second head of the charge was inconsistent with the finding in her favour on the first. He submitted that the evidence showed that she treated all her patients in a similar way, including $\mathrm{Mr} \mathrm{A}$. But the three law lords-Lords Keith of Kinkel, Mackay of Clashfern, and Goff of Chieveleyrejected the submission. Lord Goff said that the first head related to a large number of addicts, and addicts were generally unwilling to give evidence. The committee had been concerned about gaps in the evidence and had found that the facts alleged had not been proved to their satisfaction. Mr A and his wife, on the other hand, were prepared to, and did, give evidence before the committee.

\section{Two schools of thought}

In his submissions the counsel for the GMC deprecated attempts to turn the inquiry into a political debate over the merits and demerits of long term prescribing of opiates for drug addicts. The council, he emphasised, recognised that there were two schools of thought on the subject; but if a practitioner embarked on a course of long term maintenance prescribing to drug addicts she should take elementary precautions, and Dr Dally had failed to do so.

In the 1960s many addicts were maintained on long term prescriptions for heroin substitutes, but in the 1970s the pendulum swung to a multidisciplinary approach together with much more restrictive prescribing. The 1984 guidelines of good clinical practice favour prescribing controlled drugs, if at all, for only a short detoxification period. But the move to curb Dr Dally's prescribing powers comes at a time when the threat of the acquired immune deficiency syndrome is giving new fuel to the debate over prescribing policy for drug addicts. One argument is that more flexible prescribing would at least draw more drug users into the clinics, which now see only a small proportion of drug abusers, and enable more influence to be exerted over the risk of infection from the human immunodeficiency virus to drug abusers and the likelihood of transmission from them to the general population.

\section{Reference} 1 Medical Working Group on Drug Dependence. Guidelines of good clinical practice in the treatment of
drug misuse. London: DHSS, 1984. (Connell report.) 